\title{
Experimental and Theoretical Studies of Inhibitive Behaviour of Millet Starch on the Corrosion of Aluminium in Sulphuric Acid Environment
}

\author{
Nwanonenyi, S.C*1, Madufor, I. $C^{2}$, Chukwujike, I.C ${ }^{3}$, Arinze, V.C ${ }^{4}$ \\ ${ }^{* 1 \& 2}$ Department of Polymer and Textile Engineering, Federal University of Technology, \\ Owerri Imo State \\ ${ }^{3}$ Department of Polymer and Textile Engineering, Nnamdi Azikiwe University, \\ Awka Anambra State
}

${ }^{4}$ Department of Mechanical Engineering, Akanu Ibiam Federal Polytechnic, Unwana Ebonyi State

Corresponding Author's E-mail: simyn22@yahoo.co.uk.

Keywords: Aluminium, Millet starch, Langmuir adsorption isotherm, Molecular dynamic simulation, Density functional theory.

\begin{abstract}
The corrosion inhibition of aluminium in $2 \mathrm{M} \mathrm{H}_{2} \mathrm{SO}_{4}$ by millet starch was investigated using gravimetric technique at $35-65^{\circ} \mathrm{C}$ and theoretical quantum chemical computations. The results indicate that millet starch functioned as a good inhibitor for acid induced corrosion of aluminium. It was found that increase in inhibition efficiency of the inhibitor was concentration dependent and also addition of potassium iodide increased inhibitive performance of the inhibitor synergistically. Furthermore, the mode of adsorption process of the inhibitor was best modeled using Langmuir adsorption isotherm at all inhibitor concentrations and temperatures studied. The trend of inhibition efficiency with temperature, calculated values of free energy, activation energy and enthalpy of adsorption was used to propose the inhibition mechanism. Theoretical chemical quantum computations were carried out using density functional theory to underscore the relationship existing between the inhibitive performance of millet starch and electronic properties of millet starch. Finally, Molecular dynamic simulations were performed using Forcite quench molecular dynamics to model lowest energy adsorption configurations of the starch molecule on Al surface and to determine the binding energy of adsorption
\end{abstract}

\section{INTRODUCTION}

Aluminium and its alloys are used extensively in various fabrication and construction applications since the inception of industrial revolution. This is as a result of distinct characteristics of aluminium which include: lightness, softness, low cost, light reflectivity, passivity, formability, heat and thermal conductivity, etc [1-2]. Unlike other metals, aluminium forms oxide film (protective film) in contact with atmospheric air thus giving the metal corrosion resistant property in many environments. However, in acidic or alkaline media at high concentration and temperature respectively the corrosion agent in the media breaks down the oxide film which subsequently exposes the bare aluminium surface to degradation [3]. Hence, the result is a huge economic and material loss together human and environmental problems. Consequently, there exists the need to protect the surface of aluminium components exposed to aggressive service environment. The exploration of natural products from plant origin as corrosion inhibitor should be of considerable great importance. This is basically due to their low cost considerations, availability, renewable sources, ecological acceptance, other chemical constituents containing hetero-atoms either in long chain system or aromatic structure that have proved to be effective inhibitors [4-8]. Over the years, detailed information on corrosion problems, control measures and material behaviour in different service environment have been reported, yet material failures still occur [9-10]. Therefore, more investigations need to be carried out to ascertain better understanding on the behaviour of metals in varying conditions. Recent literature has shown that despite many sources of starch, only relative few have been explored in inhibiting the corrosion of aluminium [11-12]. 
Chemical quantum computations have proved to be of great importance in determining the molecular structure of the inhibitor, the electronic structure of metals, and as well as the interaction existing between the between inhibitor and metal. For instance, density functional theory (DFT) - a based quantum chemical computation has provided a useful framework for developing new method for predicting, rationalizing and eventually having deeper understanding of inhibitive effectiveness of inhibitors at molecular level and as well as many aspects of chemical reaction processes [13-21]. This is due to the ability of DFT in including some effects of electronic molecular structure and inhibition efficacy correlation in its computational analysis. The present study is designed as a contribution to the growing demand on the need for environmental friendly corrosion inhibitors to (i) establish the efficacy of millet starch as corrosion inhibitor (ii) to determine the effect of temperature on the corrosion process in the absence and presence of millet starch (iii) to ascertain whether the experimentally predicted inhibitive performance of millet starch is fully supported by the theoretically predicted quantum chemical parameters such as $\mathrm{E}_{\mathrm{HOMO}}, \mathrm{E}_{\mathrm{LUMO}}$, the energy gap $(\Delta \mathrm{E})$ between $\mathrm{E}_{\mathrm{HOMO}}$ and $\mathrm{E}_{\mathrm{LUMO}}$, etc.

\section{MATERIAL AND METHODS}

\section{Material preparation}

The aluminium sheet of type AA 1060 and purity 98\% was used for the corrosion inhibition studies. The specimens of size $4 \times 31 \mathrm{~cm}$ was press from the sheet, machined and polished with series of emery papers. This was followed by rinsing the specimen with acetone and washing with doubledistilled water finally dried in hot air and stored in desiccators. The BHD grade $\mathrm{H}_{2} \mathrm{SO}_{4}$ and distilled water were used to prepare $2 \mathrm{M} \mathrm{H}_{2} \mathrm{SO}_{4}$ solution by serial dilution principle. The millet starch used as inhibitor was extracted from the millet grains and pre-gelatinized to obtain cold water soluble starch using the methods described elsewhere [22]. The different concentrations $(0.5 \mathrm{~g} / \mathrm{L}-2.5 \mathrm{~g} / \mathrm{L})$ of inhibitor solutions were prepared by dissolving specified amount of inhibitor in $2 \mathrm{M} \mathrm{H}_{2} \mathrm{SO}_{4}$ solution. $0.5 \mathrm{~g}$ of potassium iodide (KI) $\mathrm{BDH}$ grade was added to each of the solutions containing inhibitor.

\section{Gravimetric measurement}

Freshly prepared aluminium coupons were suspended in $250 \mathrm{~mL}$ capacity beakers containing 200 $\mathrm{mL}$ of test solution equilibrated at $35-65^{\circ} \mathrm{C}$ in a thermostatic water bath with the aid of glass rod, nylon rope and hooks. The coupons were retrieved at $4 \mathrm{~h}$ interval progressively for $24 \mathrm{~h}$. The weight loss obtained was the difference between the initial weight of coupons before suspending in the test solution and the final weight of coupons after suspending in the test solution. The values recorded were mean values of triplicate determinations. The corrosion rate (CR) values were determined from the equation stated below [23].

$$
\mathrm{CR}(\mathrm{mm} / \mathrm{yr})=\left(\frac{87600 \Delta \mathrm{W}}{\rho \mathrm{At}}\right)
$$

where, $\Delta \mathrm{W}=$ weight loss in $\operatorname{gram}(\mathrm{g}), \rho=$ density of the metal coupons $\left(\mathrm{g} / \mathrm{cm}^{3}\right), \mathrm{A}=$ exposed surface area of the metal coupon $\left(\mathrm{cm}^{2}\right)$ and $\mathrm{t}=$ time of exposure (in $\mathrm{hrs}$ ).

The percentage inhibition efficiency, \% IE was calculated respectively using the equation stated below [24]:

$$
\% \mathrm{IE}=1-\left(\frac{\mathrm{CR}_{0}}{\mathrm{CR}_{\mathrm{i}}}\right) \times 100
$$

where $\mathrm{CR}_{\mathrm{i}}$ and $\mathrm{CR}_{\mathrm{o}}$ are corrosion rates in the presence and absence of inhibitor respective The degree of surface coverage $(\theta)$ was calculated by using the expression stated below [25]:

$$
\theta=1-\left(\frac{\mathrm{CR}_{0}}{\mathrm{CR}_{\mathrm{i}}}\right)
$$




\section{Chemical quantum computational studies}

The density functional theory (DFT) was used to optimize the geometry of the glucose unit of starch molecules in order to establish the correlation existing between the inhibition efficiency and electronic structure of starch molecule. The electronic structure of glucose unit of starch molecule was modelled within the framework of density functional theory (DFT) electronic structure programs, Forcite and $\mathrm{DMol}^{3}$ using Mulliken population analysis as contained in Materials Studio 7.0 software (Accelrys Inc.). Electronic parameters for the simulation include restricted spin polarization using the DNP basis set and the Perdew Wang (PW) local correlation density functional. Molecular dynamic simulation was performed to understand the inhibitive performance of the millet starch at the molecular level.

\section{RESULTS AND DISCUSSION}

\section{Weight loss, corrosion rates and inhibition efficiency}

The dissolution of aluminium coupons in $2 \mathrm{M} \mathrm{H}_{2} \mathrm{SO}_{4}$ in the absence and presence of different concentrations millet starch for $24 \mathrm{~h}$ was determined at $35-65^{\circ} \mathrm{C}$ using weight loss technique. It is seen clearly in Fig. 1 the linear variation between the weight loss of aluminium coupons and time, and much lower values of weight loss were obtained in inhibited solution than in the blank solution. Similar curves were obtained for the other temperatures (not shown). The linear relationship obtained is an indication that there is no passive behaviour exhibited by aluminium within stipulated time of study. Again, the lower values of weight loss obtained in the inhibited solution showed that starch molecules were first adsorbed onto the aluminium surface and impede the corrosion process thereafter. Hence, the adsorbed layer exhibited gradual weakening effect with time during corrosion process.

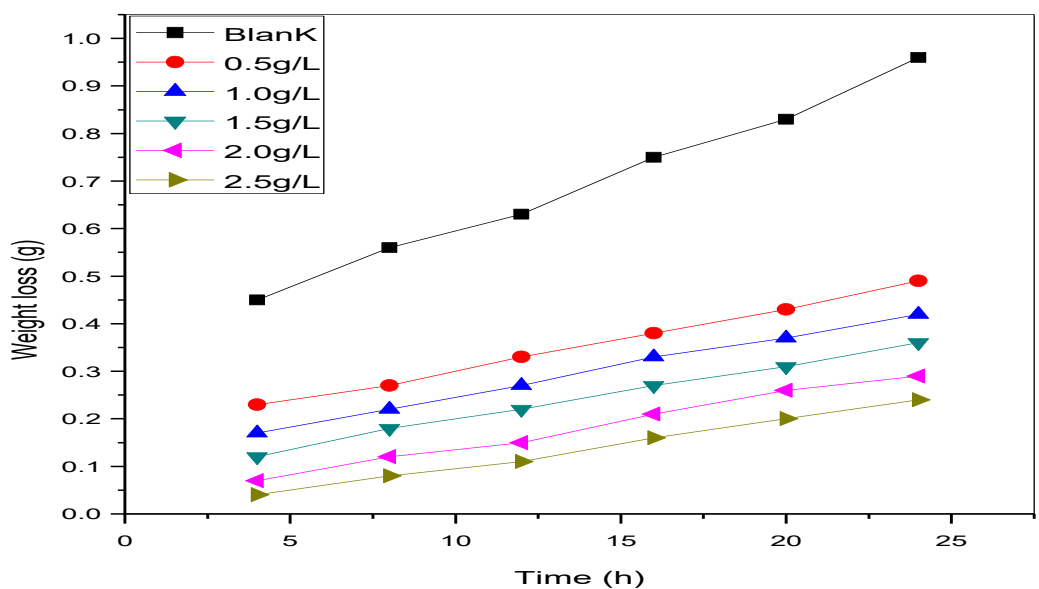

Fig. 1: Plot of weight loss versus time for aluminium corrosion in $2 \mathrm{M} \mathrm{H}_{2} \mathrm{SO}_{4}$ in the absence and presence of different concentrations of millet starch at $35^{\circ} \mathrm{C}$.

Fig. 2 exhibits the effects of different concentrations of millet starch on the corrosion rates of aluminium coupons in $2 \mathrm{M} \mathrm{H}_{2} \mathrm{SO}_{4}$ solution after $24 \mathrm{~h}$ exposure. It is clearly shown (Fig.2 and Table 1) that corrosion rates are reduced in the presence of millet starch as compared to free acid solution. Also, the rate of corrosion increased with increase in temperature at all concentrations studied. The reduction in corrosion rate of aluminium in acidic could be attributed to the adsorption of the organo-metallic complexes formed between the starch molecules and aluminium surface, which reduce the free corrosion sites on aluminium surface and thus decrease the corrosion process. The adsorption of starch molecules on the aluminium surface can be as a result the interaction between the lone pair of electrons of the oxygen atom of glucose unit and aluminium surface. Hence, the presence of vacant $d$ orbital of low energy in the aluminium atom facilitates the process of adsorption 
Table 1: Calculated values of corrosion rate $(\mathrm{mm} / \mathrm{yr})$ and inhibition efficiency (\%) for aluminium corrosion in $2 \mathrm{M} \mathrm{H}_{2} \mathrm{SO}_{4}$ in the absence and presence different concentrations of millet starch and iodide mixture at $35-60^{\circ} \mathrm{C}$.

\begin{tabular}{lcccccccc}
\hline System/ Conc & \multicolumn{3}{c}{ Corrosion rate $\mathbf{( m m} / \mathbf{y r})$} & \multicolumn{4}{c}{ Inhibition efficiency (\%) } \\
& $\mathbf{3 5}^{\mathbf{O}} \mathbf{C}$ & $\mathbf{4 5}^{\mathbf{0}} \mathbf{C}$ & $\mathbf{5 5}^{\mathbf{0}}$ & $\mathbf{6 5}^{\mathbf{0}}$ & $\mathbf{3 5}^{\mathbf{O}} \mathbf{C}$ & $\mathbf{4 5}^{\mathbf{0}}$ & $\mathbf{5 5}^{\mathbf{0}}$ & $\mathbf{6 5}^{\mathbf{O}} \mathbf{C}$ \\
\hline Blank & 24.53 & 29.34 & 37.08 & 44.17 & - & - & - & - \\
$0.5 \mathrm{~g} / \mathrm{L}$ & 7.73 & 10.75 & 15.92 & 19.91 & 68.49 & 63.36 & 57.07 & 54.92 \\
$1.0 \mathrm{~g} / \mathrm{L}$ & 5.43 & 8.26 & 13.05 & 16.96 & 75.86 & 71.85 & 64.81 & 61.60 \\
$1.5 \mathrm{~g} / \mathrm{L}$ & 3.21 & 6.98 & 10.95 & 14.73 & 80.91 & 76.21 & 70.47 & 66.65 \\
$2.0 \mathrm{~g} / \mathrm{L}$ & 2.87 & 5.75 & 8.81 & 11.75 & 84.30 & 80.40 & 76.24 & 73.40 \\
$2.5 \mathrm{~g} / \mathrm{L}$ & 2.21 & 3.85 & 6.52 & 9.71 & 88.99 & 85.88 & 82.41 & 78.02 \\
$0.5 \mathrm{~g} / \mathrm{L}+0.5 \mathrm{gKI}$ & 6.13 & 8.43 & 12.34 & 17.55 & 73.16 & 69.08 & 65.42 & 59.80 \\
$1.5 \mathrm{~g} / \mathrm{L}+0.5 \mathrm{gKI}$ & 3.42 & 4.25 & 7.63 & 11.62 & 84.13 & 80.51 & 75.42 & 70.96 \\
$2.5 \mathrm{~g} / \mathrm{L}+0.5 \mathrm{gKI}$ & 2.04 & 3.27 & 5.06 & 8.17 & 93.27 & 89.49 & 85.62 & 81.56 \\
\hline
\end{tabular}

The inhibitive efficacy of millet starch in retarding the dissolution of aluminium coupons in $2 \mathrm{M}$ $\mathrm{H}_{2} \mathrm{SO}_{4}$ was obtained by comparing the corrosion rates of the aluminium coupon in the presence of millet starch and in the free acid solution and expressed in terms of the inhibition efficiency (\%). Fig. 3 and Table 1 clearly illustrate the relationship between the inhibition efficiency and concentration in $2 \mathrm{M} \mathrm{H}_{2} \mathrm{SO}_{4}$ at $35-65^{\circ} \mathrm{C}$. The increase in inhibition efficiency with increasing millet starch concentration is an indication that more starch molecules are adsorbed on the aluminium surface, thus leading to the formation of protective layer onto aluminium surface.

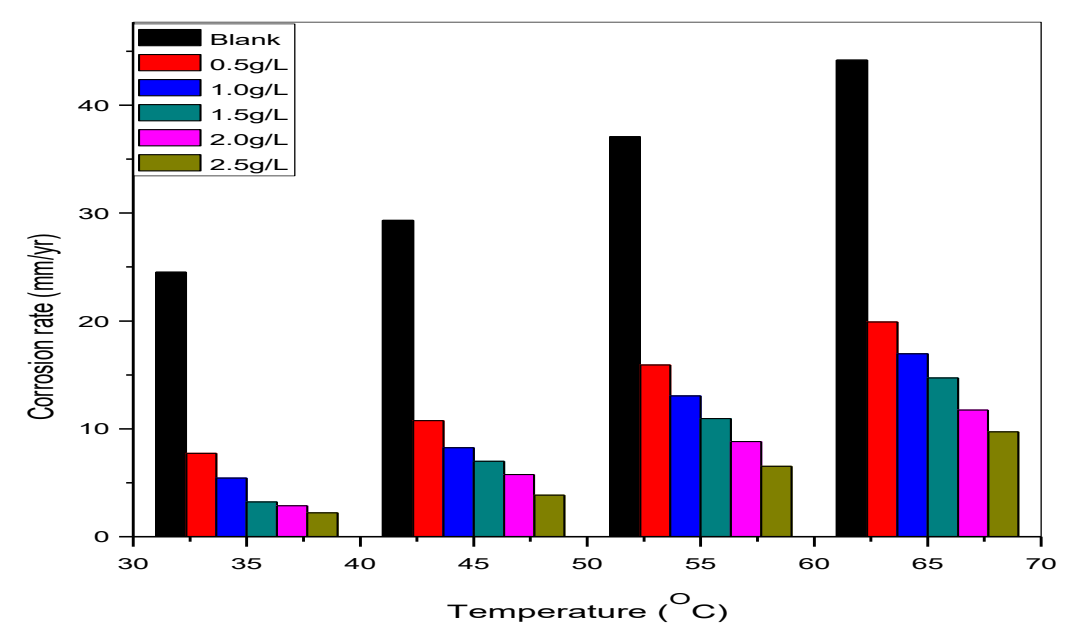

Fig. 2: Plot of corrosion rate versus temperature in the absence and presence of different concentrations of millet starch.

The decrease in inhibition efficiency with increasing temperature suggests weakening of the potency of the millet starch as inhibitor and possible desorption of some of the adsorbed starch molecules from aluminium surface. This behaviour shows that the adsorption of millet starch on aluminium surface is by physical mechanism. The decrease in inhibition efficiency with increase in temperature may due to the fact that increase in temperature decrease the equilibrium of adsorption, decrease inhibition performance by activating the corrosion rates and reduce the tendency of starch adsorption on the aluminium surface. 


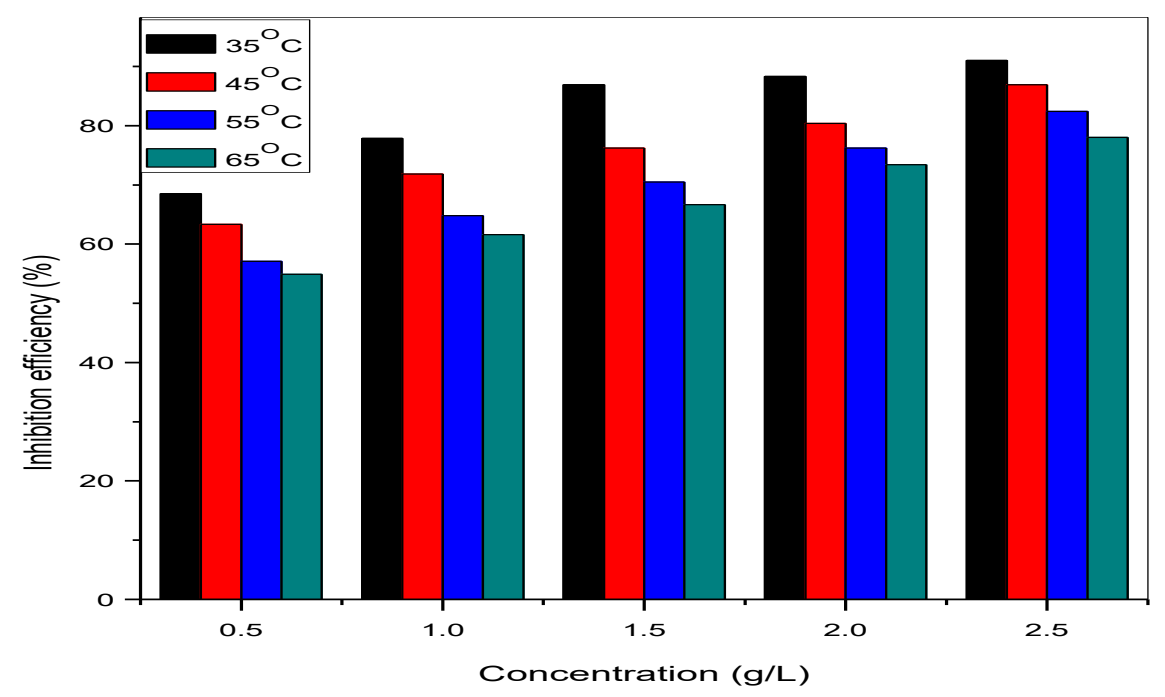

Fig. 3: Plot of inhibition efficiency versus concentration at different temperatures

\section{Adsorption and thermodynamic studies}

The increase in the efficiency of inhibition by millet starch with increase in concentration is attributed to the adsorption of millet starch on the aluminium surface. It shows that millet starch is adsorbed on the aluminium surface at higher concentration leading to greater surface coverage and theoretically confirmed by fitting the experimental values of degree of surface coverage $(\theta)$ to different adsorption isotherms and explaining the best fit isotherm for the adsorption process using the value of correlation co-efficient $\left(\mathrm{R}^{2}\right)$. The data were tested graphically and the best result was obtained for Langmuir adsorption isotherm.

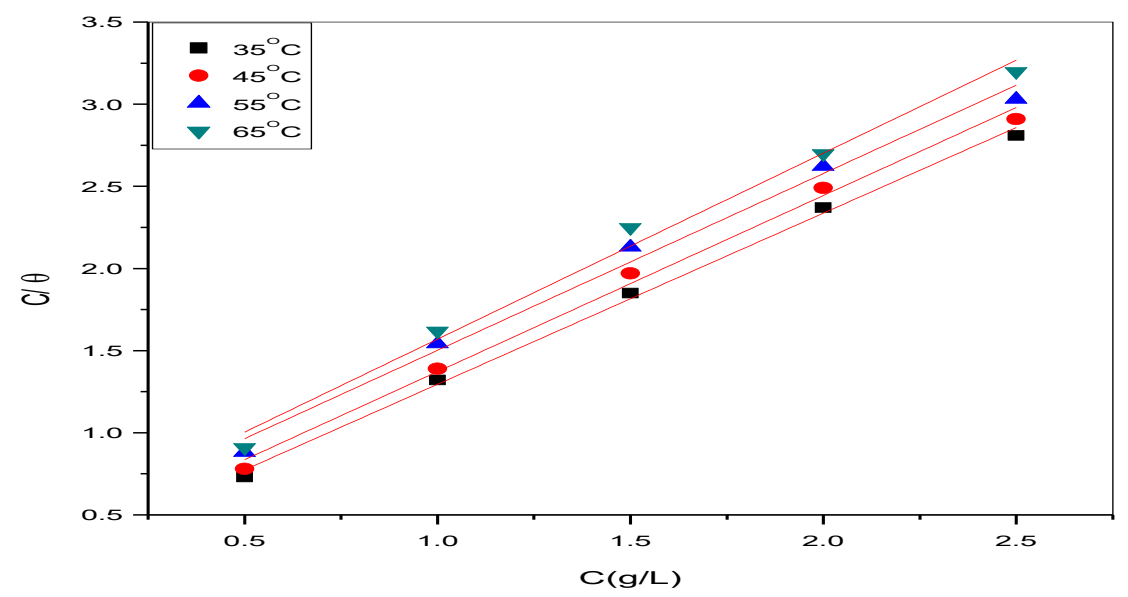

Fig. 4: Langmuir adsorption isotherm for starch at $35-65^{\circ} \mathrm{C}$

The plots of $\mathrm{C} / \theta$ against $\mathrm{C}$ which are features of Langmuir adsorption isotherm is given by the equation stated below [12]:

$$
\frac{\mathrm{C}}{\theta}=\frac{1}{\mathrm{~K}_{\mathrm{ads}}}+\mathrm{C}
$$

where $\theta=$ degree of surface coverage, $\mathrm{C}=$ inhibitor concentration, $\mathrm{K}_{\mathrm{ads}}=$ equilibrium constant of adsorption process. The plots of $\mathrm{C} / \theta$ against $\mathrm{C}$ at $35-65^{\circ} \mathrm{C}$ gave a straight line for dissolution of aluminium in $2 \mathrm{M} \mathrm{H}_{2} \mathrm{SO}_{4}$ in the presence of millet starch alone and in combination with potassium iodide (Fig. 4 \& Fig. 5). The co-efficient of linear correlation $\left(\mathrm{R}^{2}\right)$ is close unity (Table 2), thus suggesting that adsorption of millet starch alone and in combination of potassium iodide on aluminium surface obeys Langmuir adsorption at all temperature studied. 


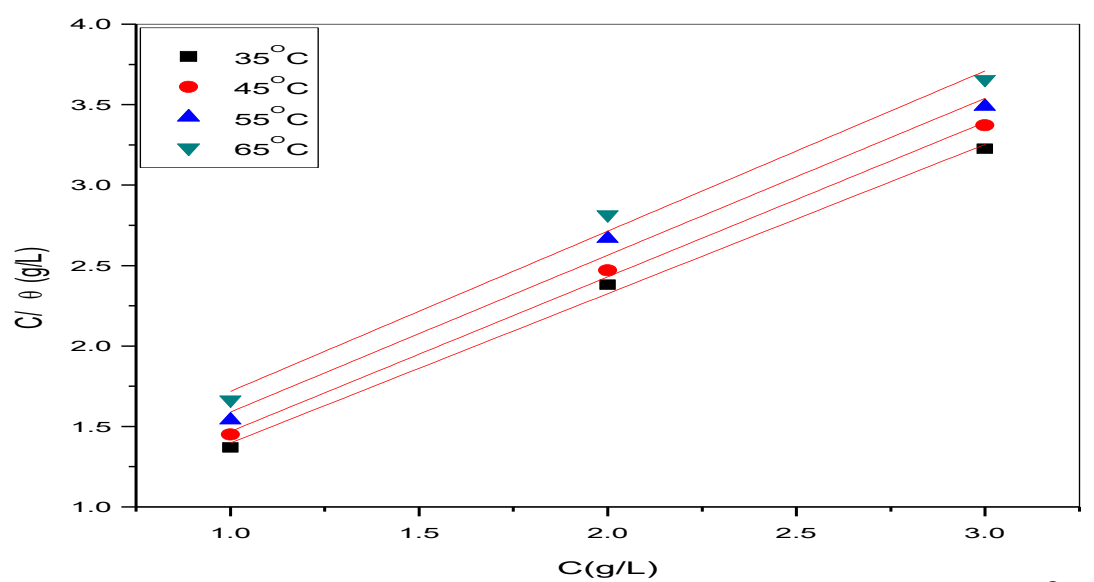

Fig. 5: Langmuir adsorption isotherm for starch $+\mathrm{KI}$ at $35-65^{\mathrm{O}} \mathrm{C}$

Free energy of adsorption, $\Delta \mathrm{G}_{\mathrm{ads}}$ is related to the equilibrium constant of adsorption process, $\mathrm{K}_{\mathrm{ads}}$ by the expression [26] stated below and the values of $\mathrm{K}_{\mathrm{ads}}$ were calculated from the intercepts of the straight lines of plot of $\mathrm{C} / \theta$ against $\mathrm{C}$.

$$
\mathrm{K}_{\mathrm{ads}}=\frac{1}{55.5} \exp \left(\frac{-\Delta \mathrm{G}^{\circ} \mathrm{ads}}{\mathrm{RT}}\right)
$$

The calculated values of free energy of adsorption, $\Delta \mathrm{G}_{\text {ads }}$ are shown in Table 2 . The negative values of $\Delta \mathrm{G}_{\mathrm{ads}}$ are an indication that there is a strong electrostatic interaction existing between the starch molecules and the aluminium surface and also spontaneous adsorption of starch molecules onto the aluminium surface. The values of $\Delta \mathrm{G}_{\text {ads }}$ are lower than $-20 \mathrm{KJ} / \mathrm{mol}$, thus suggesting that physical adsorption mechanism. Furthermore, the increase in $\Delta \mathrm{G}_{\mathrm{ads}}$ (becoming less negative) with rise in temperature reveals that the inhibition of aluminium by millet starch is an exothermic process. The exothermic process does not favour adsorption because with rise in temperature inhibitor desorbs from the aluminium surface.

Table 2: Some Langmuir adsorption parameters for dissolution of aluminium coupons in $2 \mathrm{M}$

\begin{tabular}{ccccc}
\multicolumn{5}{c}{$\mathrm{H}_{2} \mathrm{SO}_{4}$} \\
\hline Temp $\left({ }^{\circ} \mathrm{C}\right)$ & $\mathrm{R}^{2}$ & $\mathrm{~K}_{\text {ads }}$ & Slope & $\Delta \mathrm{G}_{\text {ads }}(\mathrm{KJ} / \mathrm{mol})$ \\
\hline 35 & 0.99 & 3.92 & 1.04 & -18.17 \\
45 & 0.99 & 3.22 & 1.07 & -13.71 \\
55 & 0.99 & 2.40 & 1.09 & -13.34 \\
65 & 0.99 & 2.35 & 1.14 & -13.69 \\
\hline
\end{tabular}

The enthalpy of adsorption process, $\Delta \mathrm{H}_{\mathrm{ads}}$ and entropy of adsorption for the inhibition process, $\Delta \mathrm{S}_{\mathrm{ads}}$ can be obtained using transition state equation expressed as follows [27]:

$$
\log \left(\frac{\mathrm{CR}}{\mathrm{T}}\right)=\log \left(\frac{\mathrm{R}}{\mathrm{Nh}}\right)+\left(\frac{\Delta \mathrm{S}_{\mathrm{ads}}}{2.303 \mathrm{RT}}\right)-\left(\frac{\Delta \mathrm{H}_{\mathrm{ads}}}{2.303 \mathrm{RT}}\right)
$$

where $\mathrm{CR}=$ corrosion rate, $\mathrm{R}=$ universal gas constant, $\Delta \mathrm{H}_{\mathrm{ads}}=$ enthalpy, $\Delta \mathrm{S}_{\mathrm{ads}}=$ entropy of adsorption process, $\mathrm{N}=$ Avogadro's constant, $\mathrm{h}=$ Planck's constant and $\mathrm{T}=$ absolute temperature. The plots of $\log (\mathrm{CR} / \mathrm{T})$ against $1000 / \mathrm{T}$ for aluminium corrosion in $2 \mathrm{M} \mathrm{H}_{2} \mathrm{SO}_{4}$ at different concentrations of millet starch and in combination with KI are shown in Fig. 6. 

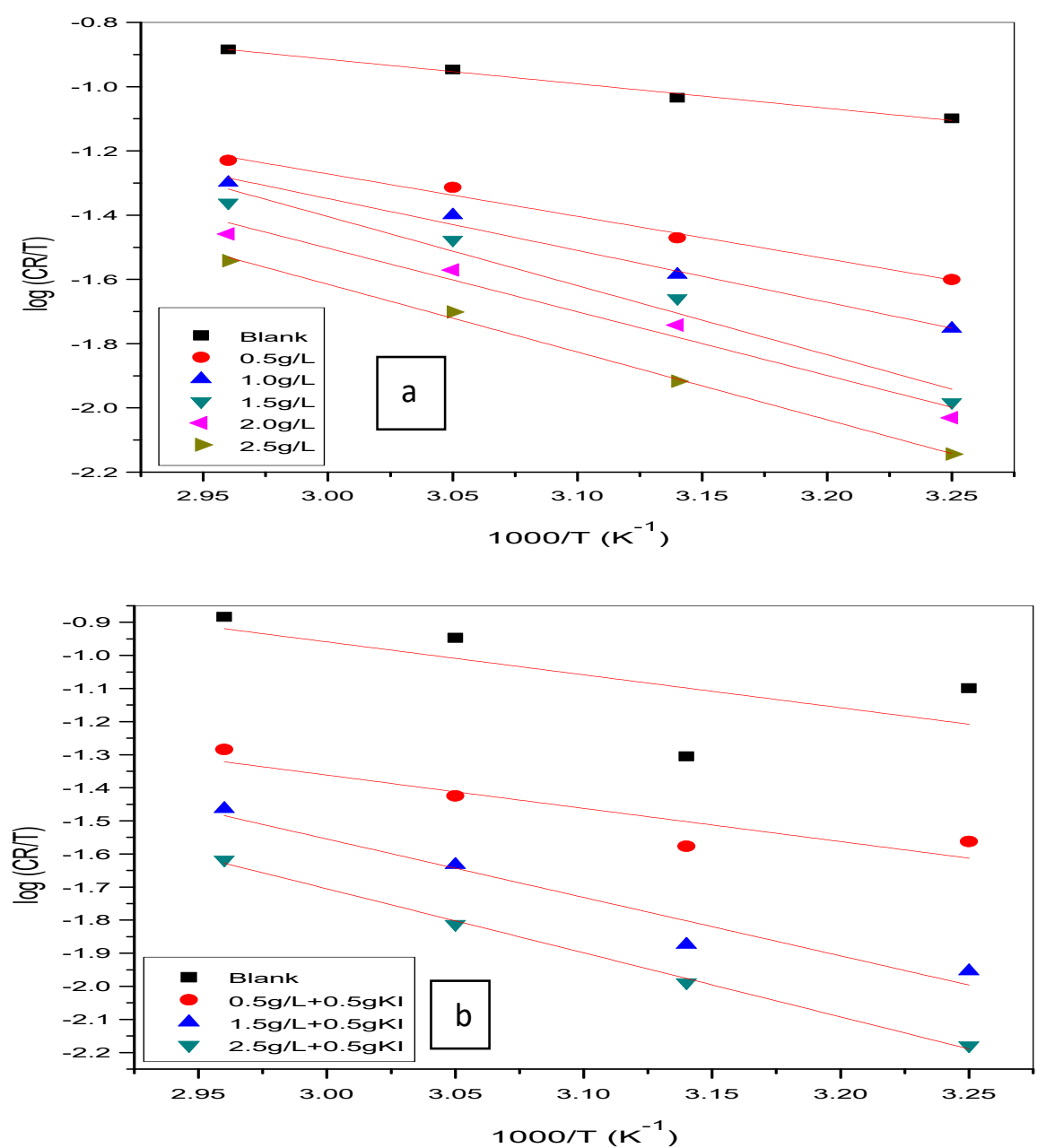

Fig. 6: Transition state plot for aluminium corrosion in $2 \mathrm{M} \mathrm{H}_{2} \mathrm{SO}_{4}$ in the (a) absence and presence of millet starch and (b) combination millet starch and KI

Straight lines were obtained with slope equal to $\left(\Delta \mathrm{H}_{\mathrm{ads}} / 2.303 \mathrm{R}\right)$ and intercept equal to [( $\log (\mathrm{R} / \mathrm{Nh})$ $+\Delta \mathrm{S}_{\mathrm{ads}}$ ) from which the values of $\Delta \mathrm{H}_{\mathrm{ads}}$ and $\Delta \mathrm{S}_{\mathrm{ads}}$ were calculated $\mathrm{r}$ and listed in Table 3 . The positive values of $\Delta \mathrm{H}_{\mathrm{ads}}$ in both absence and presence of inhibitors reflect the endothermic nature of the aluminium dissolution process. The negative values of $\Delta \mathrm{S}_{\mathrm{ads}}$ implies that inhibitor molecules move freely in the bulk solution and adsorbed in an orderly manner onto the aluminium surface which results in decrease in entropy [28]. In addition, the large negative values of $\Delta \mathrm{S}_{\mathrm{ads}}$ in both uninhibited and inhibited solutions reflects that activated complex in the rate determining steps represent association rather dissociation steps [27].

Table 3: Some thermodynamic parameters for dissolution of aluminium in $2 \mathrm{M} \mathrm{H}_{2} \mathrm{SO}_{4}$ in the Absence and presence of millet starch, and millet starch + potassium iodide mixtures.

\begin{tabular}{lrcc}
\hline $\begin{array}{l}\text { System/ } \\
\text { Conc }\end{array}$ & $\Delta \mathrm{H}_{\text {ads }}(\mathrm{KJ} / \mathrm{mol})$ & $\Delta \mathrm{S}_{\text {ads }}(\mathrm{KJ} / \mathrm{mol})$ & $\Delta \mathrm{E}_{\mathrm{a}}(\mathrm{KJ} / \mathrm{mol})$ \\
\hline Blank & 14.58 & -171.37 & 17.25 \\
$0.5 \mathrm{~g} / \mathrm{L}$ & 25.29 & -146.04 & 28.43 \\
$1.0 \mathrm{~g} / \mathrm{L}$ & 30.89 & -130.73 & 33.57 \\
$1.5 \mathrm{~g} / \mathrm{L}$ & 41.16 & -100.98 & 43.84 \\
$2.0 \mathrm{~g} / \mathrm{L}$ & 37.93 & -113.24 & 40.60 \\
$2.5 \mathrm{~g} / \mathrm{L}$ & 40.36 & -107.42 & 43.03 \\
$0.5 \mathrm{~g} / \mathrm{L}+0.5 \mathrm{gKI}$ & 27.83 & -139.96 & 30.51 \\
$1.5 \mathrm{~g} / \mathrm{L}+0.5 \mathrm{gKI}$ & 33.80 & -125.95 & 36.48 \\
$2.5 \mathrm{~g} / \mathrm{L}+0.5 \mathrm{gKI}$ & 37.06 & -119.04 & 39.75 \\
\hline
\end{tabular}




\section{Effect of temperature}

In this study the effect of temperature on the dissolution of aluminium in $2 \mathrm{M} \mathrm{H}_{2} \mathrm{SO}_{4}$ and its inhibition by millet starch alone and combination of millet starch and potassium iodide was determined using weight loss method at temperature range $35-65^{\circ} \mathrm{C}$.
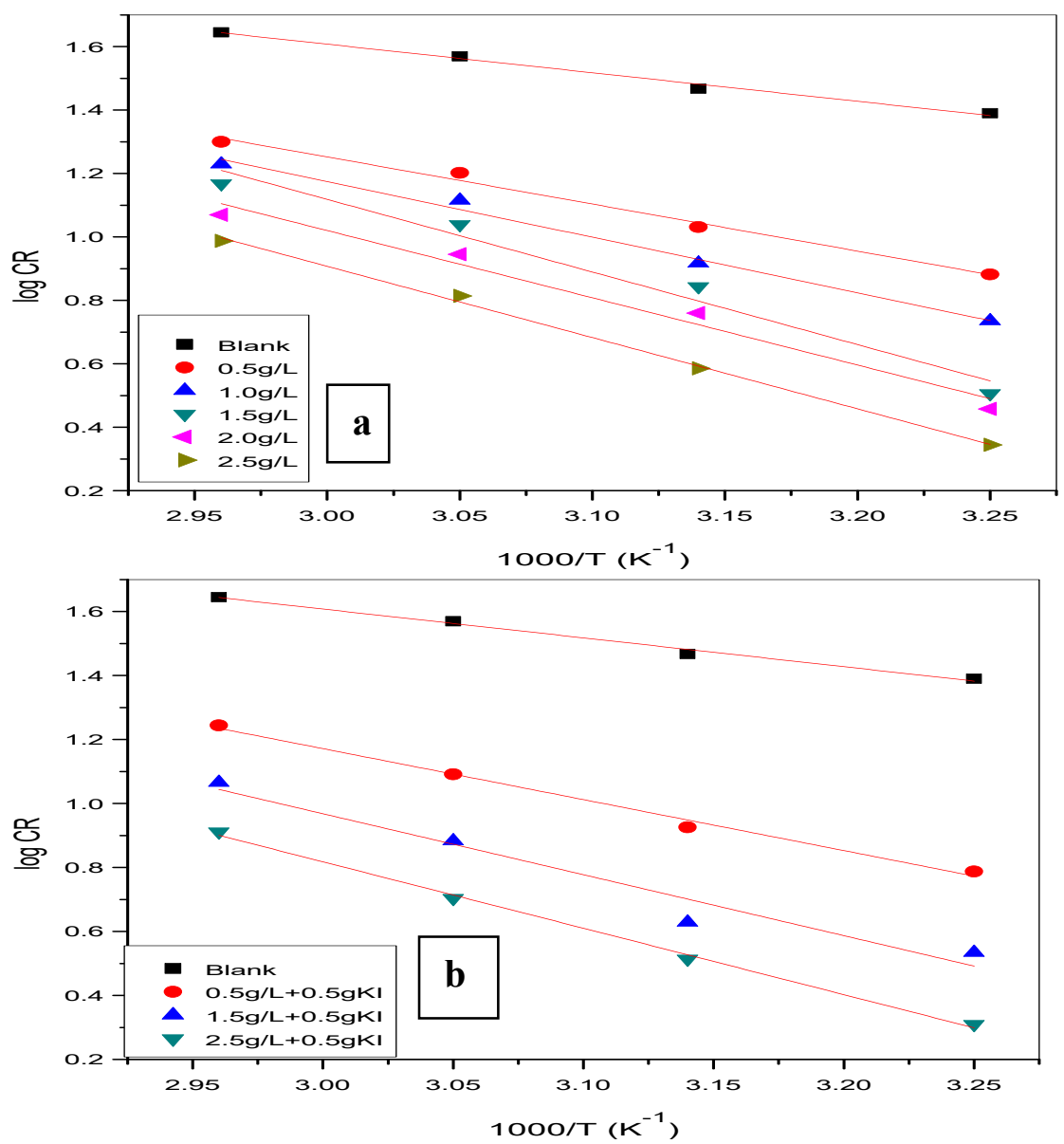

Fig. 7: Arrhenius plot for corrosion of aluminium in $2 \mathrm{M} 2 \mathrm{M} \mathrm{H}_{2} \mathrm{SO}_{4}$ in the (a) absence and presence of millet starch and (b) combination of millet starch and Potassium iodide.

The results of temperature effect on the corrosion rate and inhibition efficiency as indicated in Table 1 show that corrosion rate increases with rise in temperature both in the free acid solution and inhibited solution whereas inhibition efficiency decreases with increase in temperature for all the different systems studied. The relationship between the corrosion rate of aluminium in acidic environment and temperature is often represented by Arrhenius equation:

$$
\log C R=\log A-\frac{E_{a}}{2.303 R T}
$$

where $\mathrm{CR}=$ corrosion rate, $\mathrm{A}=$ Arrhenius constant, $\mathrm{Ea}=$ apparent activation energy, $\mathrm{R}=$ universal gas constant and $\mathrm{T}=$ absolute temperature. The plot of $\log \mathrm{CR}$ against 1000/ $\mathrm{T}$ for aluminium dissolution in $2 \mathrm{M} \mathrm{H}_{2} \mathrm{SO}_{4}$ in the absence and presence of different concentrations millet starch is presented in Fig. 7. Linear plots were obtained and activation energy, $E_{a}$ was determined from the slope $(-\mathrm{Ea} / 2.303 \mathrm{R})$ of the linear plots and listed in Table 3 . It seen in Table 3 that values of activation energy, $E_{a}$ are higher in the inhibited solutions than in the uninhibited solution. This is an indication that a strong inhibitive action occurred which increase the energy barrier for the corrosion process and also reflects the electrostatic character of the millet starch's adsorption on the aluminium surface. Hence, this supports the proposed adsorption inhibition mechanism (physisorption) [27]. 


\section{Effect of potassium iodide addition}

In acidic solution, organic compounds exist either as protonated species or molecular form. During metal corrosion, molecules of organic compounds adsorb onto the metal surface through the displacement reaction process. Then, protonated species retard the active cathodic reaction and reduce the hydrogen gas evolution, whereas the molecular species slow down the activities anodic reaction and metal dissolution process. Synergistic increase in the inhibition efficiency of mixtures of inhibitor and halide ions is an indication that protonated species in the inhibitor contributed significantly in the inhibitive effect of the inhibitor. On the other hand, the negligible effect in the inhibition efficiency of mixtures of inhibitor and halide ions implies that molecular species in the inhibitor are more active or effective [29].

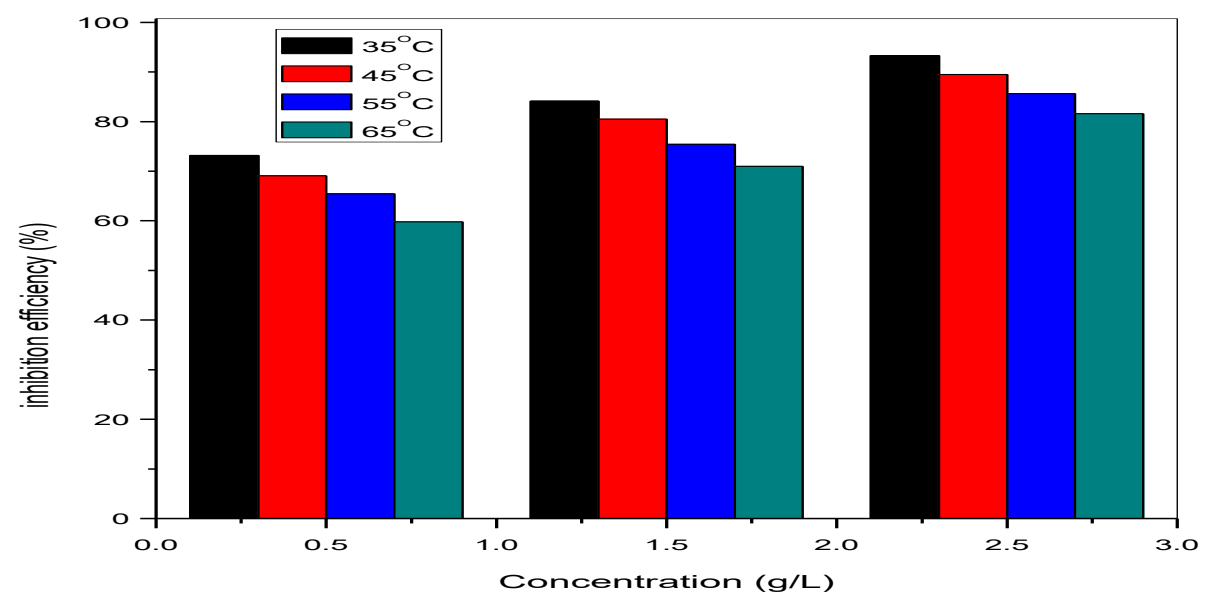

Fig. 8: Plot of variation of inhibition efficiency with concentrations of millet starch in the $0.5 \mathrm{~g}$ potassium iodide

Table 1 and Fig. 8 clearly indicate that potassium iodide remarkable improved the inhibition efficiency of the millet starch in $2 \mathrm{M} \mathrm{H}_{2} \mathrm{SO}_{4}$, thus emphasizing the contributive effect of protonated speices of the inhibitor and synergistic effective of mixtures of potassium iodide and millet starch which result in better inhibition efficiency and surface coverage. This contributive effect of potassium iodide in enhancing the inhibition efficiency of millet starch or retarding the dissolution of aluminium in $2 \mathrm{M} \mathrm{H}_{2} \mathrm{SO}_{4}$ is dependent (a) nature and surface charge of the metal (b) electrostatic field set up by the negative charge of the anion on adsorption sites and (c) type of aggressive solution (d) structure of inhibitor (e) reaction temperature [30-32]

\section{Mechanism of inhibition}

Starch is a polysaccharide and structurally consists of mixture of two glucose polymers namely linear amylase and branched amylopectin chain. The anhydro $-\mathrm{D}-$ glucose units in amylose are linked through $\alpha-(1 \rightarrow 4)$ glucosidic bonds whereas in amylopectin the anhydro $-\mathrm{D}$ - glucose units are linked through $\alpha-(1 \rightarrow 6)$ glucosidic bonds. In acidic solution, starch is hydrolyzed partially into simpler carbohydrates (glucose unit) by breaking down the glucosidic bonds. Hence, this causes the solubilization of starch granule resulting in products that are more readily dispersible and of low viscosities, and which are likely to go into bulk water. It is only negligible starch molecules undergo hydrolysis and desorbs from metal surface due slow hydrolysis. Hence, starch is still an effective inhibitor after slow hydrolysis.

\section{Computational studies}

In order to determine the effect of molecular structure on the effectiveness of inhibition efficiency, quantum chemical calculations were performed using density functional theory, and all calculations were carried out with the optimized geometrical structure of the glucose unit of starch molecules. The optimized structure, electron density and frontier molecular orbital (highest occupied molecular 
orbital, HOMO and lowest unoccupied molecular orbital, LUMO) of the glucose unit of the starch molecule are shown in Fig. 9. The significant parameters for the prediction of the chemical reactivity of the molecule are the energies of the frontier molecular orbital ( $\mathrm{E}_{\mathrm{HOMO}}$ and $\mathrm{E}_{\mathrm{LUMO}}$ ). $\mathrm{E}_{\text {HОмо }}$ is associated with the ability of the inhibitor molecules to donate electron and high values of $\mathrm{E}_{\mathrm{HOMO}}$ is indicating that the inhibitor molecule has strong tendency to donate electrons to a metal with unoccupied molecular orbital. $\mathrm{E}_{\mathrm{LUMO}}$ represents the tendency of the inhibitor molecules to accept electrons from the metal surface and low value of $E_{\mathrm{LUMO}}$ is signifying the easier acceptance of electrons from the metal surface. Another important parameter is the energy gap $(\Delta \mathrm{E})$ between the energy of HOMO and LUMO orbital. The inhibitor molecule with low $\Delta \mathrm{E}$ values give high inhibition efficiencies because of the reduction in the energy needed to remove an electron from the last occupied orbital. Hence, low values of $\Delta \mathrm{E}$ means good protection efficiency. The values of $\mathrm{E}_{\mathrm{HOMO}}, \mathrm{E}_{\mathrm{Lumo}}$, and $\Delta \mathrm{E}$ obtained from our calculations are $-0.5991 \mathrm{eV},-0.0842 \mathrm{eV}$ and $0.5149 \mathrm{eV}$ respectively (Table 4). A flat-lying adsorption orientation is expected, because the electron density is spread all around the glucose unit of starch molecules.

\section{Molecular dynamics simulation}

Molecular dynamic simulation was carried out to show the interaction existing between the glucose molecule and the corroding aluminium to underscore the inhibitor adsorption process at the molecular level. Simulations were performed using Forcite quench molecular dynamics in the MS modeling software 7.0 to model many different low energy adsorption configurations of the glucose unit of starch molecules on Al surface and to determine the global energy minimum. Glucose unit of starch molecules and Al crystal structure were geometrically optimized using COMPASS force field. Al has a density packed surface and the most stabilization at this position, hence Al crystal was cleaved along the (110) plane. The geometry of the lower layers of the Al slab was constrained. Forcite quench dynamic simulation was done using the optimized structure of the glucose unit of starch and Al. Calculations were performed in a 12 x 10 supercell using the COMPASS force field, QEq charge and the Smart algorithm with NVE (microanonical) ensemble, a time step of $1 \mathrm{fs}$, and simulation time $5 \mathrm{ps}$. The temperature was fixed at $298.0 \mathrm{~K}$. The system was quenched every 250 steps. Fig. 10 shows the optimized (lowest energy) adsorption structures for glucose unit of starch molecules on the Al (110) surface from the simulation. The binding energy (Ebinding) which is important in characterizing the adsorption of glucose molecule onto the Al surface was estimated using the expression:

$$
\text { EBinding }=\text { ETotal }-(\text { EGlucose }+ \text { EAl })
$$

where EGlucose $=$ energy of single glucose molecules, EAl = energy of Al slab without adsorption and ETotal $=$ total energy of the system containing a molecule and Fe surface, respectively. The obtained adsorption energy value is $-34.36762669 \mathrm{eV}$. The value was estimated by averaging the energies of five structures of lowest energy. The negative value of binding energy is an indication that the theoretical study is in agreement with the experimental findings. It is also pointing that the adsorption of glucose unit of starch molecules on the Al surface is exothermic process. 


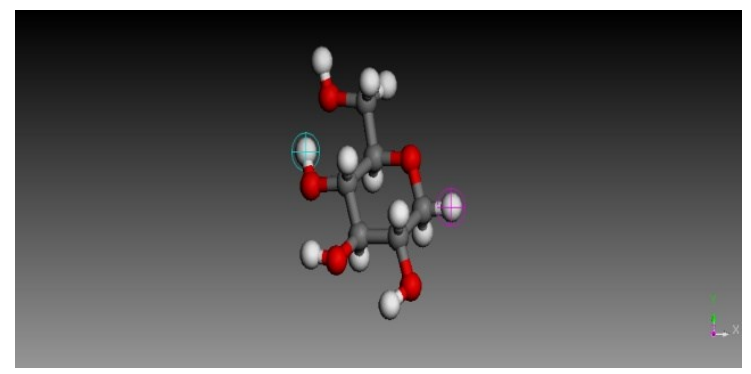

(a) Optimized structure

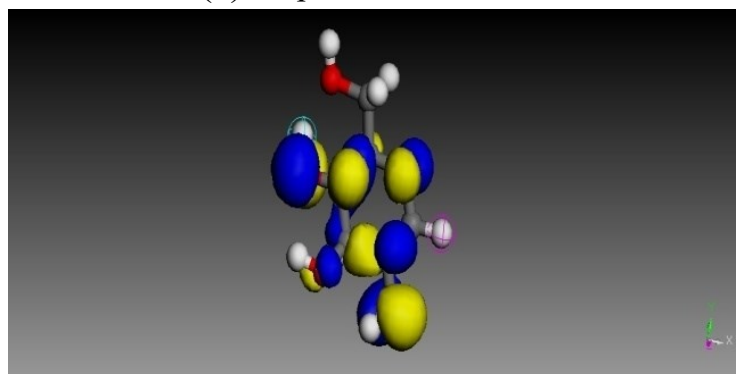

(c) HOMO orbital

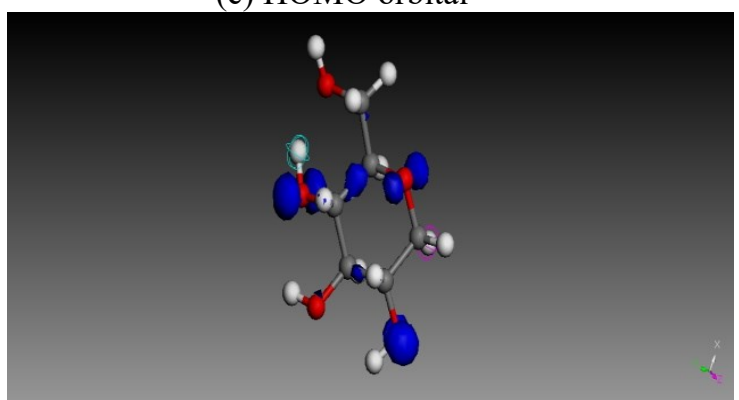

(e) Fukui function Electrophilic attack

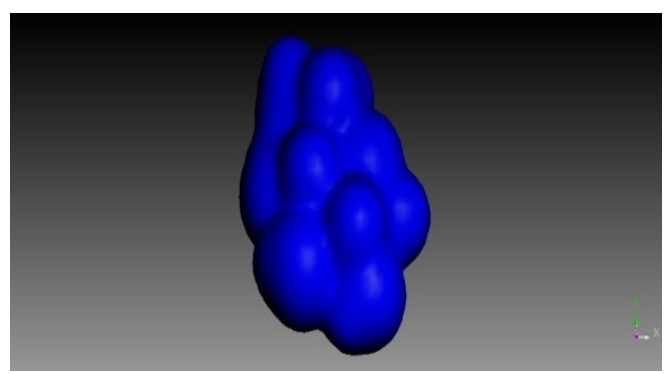

(b) Electron density

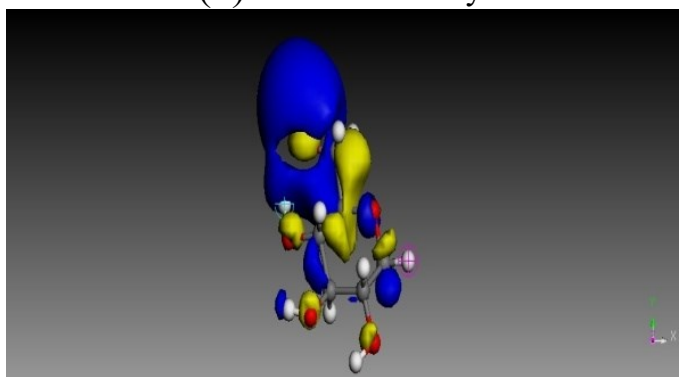

(d) LUMO orbital

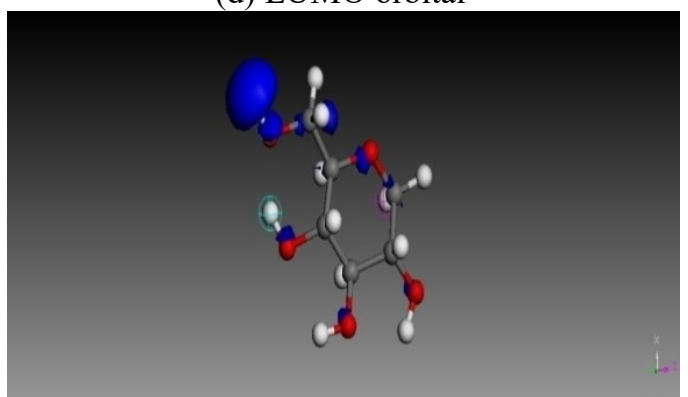

(f) Fukui function for Nucleophilic attack

Fig. 9: Electronic properties of glucose unit of starch molecule (a) optimized structure (b) electron density, (c) HOMO orbital (d) LUMO orbital, (e) fukui function for electrophilic attack ( $\mathrm{F}^{-}$), (f) fukui function for nucleophilic attack $\left(\mathrm{F}^{+}\right)$; Atom legend: white $=\mathrm{H}$; gray $=\mathrm{C}$; red $=\mathrm{O}$; The blue and yellow isosurfaces depict the electron density difference: the blue regions show electron accumulation while the yellow regions show electron loss.
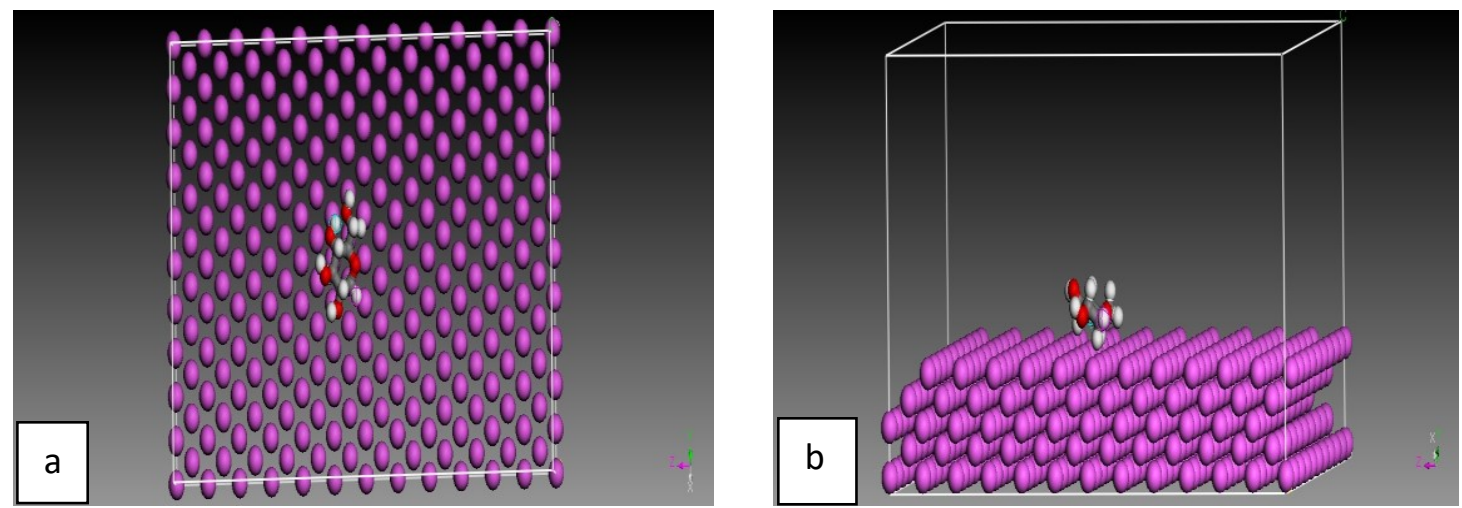

Fig. 10: Molecular dynamics model showing (a) top view and (b) side view of the adsorption of single glucose unit of starch molecules on Al (110) surface.

\section{Conclusions}

1. Millet starch was found to be a good inhibitor for dissolution of aluminium in $2 \mathrm{M} \mathrm{H}_{2} \mathrm{SO}_{4}$.

2. The increase in inhibition efficiency of millet starch was concentration dependent, decreased with rise in temperature and increased synergistically on addition of potassium iodide.

3. The mode of adsorption of millet starch alone and in combination with potassium iodide was best modeled using Langmuir adsorption isotherm. 
4. The trend of inhibition efficiency with temperature was used to propose the inhibition adsorption mechanism. The proposition was further corroborated by the calculated values of free energy of adsorption and enthalpy of adsorption

\section{Acknowledgements}

The authors are grateful to the Department of Polymer and Textile Engineering, Federal University of Technology Owerri for its assistance in providing some of the equipment used in carrying out some measurements.

\section{References}

[1] E.E. Oguzie, C.O. Akalezi, C.K. Enenebeaku and J.N. Aneke, Corrosion inhibition and adsorption behaviour of malachite green dye on aluminium corrosion, Chemical Engineering Communications, 198 (2011) 46-60.

[2] V. Kumpawat, U. Garg and R.K. Tak, Corrosion inhibition of aluminium in acid mediaby naturally occurring plant Artocarpus heterophyllus and Acacia Senegal, Jounal of Indian Council of Chemists, 26 (2009) $82-84$.

[3] M. Kliskic, J. Radosevic, S. Gudic and V. Katallinic, Aqueous extract of Rosmarinus officinalis Leaves as inhibitor of Al-Mg alloy corrosion in chloride solution, Appl. Electrochem., 30 (2000) 4039-4047.

[4] E.E. Oguzie, Studies on the inhibitive effect of Occimumviridis extract on the acid corrosion of mild steel, Mater Chem Phys, 99 (2006) 441-446.

[5] E.E. Oguzie, Evaluation of the inhibitive effect of some plant extracts on the acid corrosion of mild steel, Corros. Sci, 50 (2008) 2993- 2998.

[6] S.A. Umoren, O. Ogbobe, I.O. Igwe and E.E. Ebenso, Inhibition of mild steel corrosion in acidic medium using synthetic and naturally occurring polymers and synergistic halide additives, Corrosion Science, 50 (2008) 1998-2006.

[7] S.A. Umoren and E.E Ebenso, Studies on the anti-corrosive effect of Raphia hookeri exudates gum-halide mixtures for aluminium corrosion in acidic medium, Pigment and Resin Technology, 37 (2008) 173-182.

[8] A.Y. El-Etre, Khillah extract as inhibitor for acid corrosion of SX 316 steel, Appl.Surf.Sci, 252 (2006) 8521-8525.

[9] J.A. Wharton, R.C. Barik, G. Kear, R.J.K. Wood, K.R. Stokes and F.C. Walsh, The corrosion of nickel-aluminum bronze in seawater, Corros. Sci 47 (2005) 3336-3367.

[10] H. Baorong, Z. Jinglei, L. Yanhu and Y. Fangying, Study on effect of seawater saliniyu on electrochemical performance of Al anodes, Department of Marine Corrosion, Institute of Oceanology, Chinese Academy of Sciences, China (2001)

[11] T. Sugama and J.E. Dubai, Polyorganosiloxane-grafted potato starch coatings for protecting aluminum from corrosion, Thin Solid Films, 289, 39-48. http://dx.doi.org/10.1016/S00406090(96)08814-1 1996.

[12] R. Rosliza and W.B. Wan Nik, Improvement of corrosion resistance of AA6061 alloy by tapioca starch in seawater. Current Applied Physics. 10, 221-29. http://dx.doi.org/10.1016/j.cap.2009.05.027. 2009

[13] E. Kraka and D. Cremer, Computer Design of Anticancer Drugs. A New Enediyne Warhead, Jour. Am. Chem. Soc., 122 (2000) 8245 - 8264.

[14] P. Hohenberg and W. Kohn, Density Functional Theory: Formalism and Implementation, 136B (1964) $864-871$.

[15] R.G. Parr and W. Yang, Density Functional Theory of Atoms and Molecules, Oxford University Press, New York (1989)

[16] M.H. Cohen, In Topics in Current Chemistry, Nalewajski RF, Ed, SpringerVerlag:Heidelberg, Germany, p.143, p183. (1996) 
[17] P. Udhayakala, Density functional theory calculations on corrosion inhibitory action of five azlactones on mild steel, Journ. of Chem and Pharm. Research, 6 (2014) 117-127.

[18] M.K. Awad, Semiempirical Investigation of the Inhibition Efficiency of Thiourea Derivatives as Corrosion Inhibitors, Jour. Electroanal.Chem., 567 (2004) 219-225.

[19] R.G. Parr and W. Yang, Density functional approach to the frontier-electron theory of chemical reactivity, Jour, Am.Chem.Soc. 106 (1984) 4049-4050.

[20] H. Chermette, Chemical reactivity indexes in density functional theory, Jour. Comp. Chem. 20 (1999) 129- 154.

[21] R.G. Parr and R.G. Perason, Absolute hardness: companion parameter to absolute electronegativity, Jour.Am.Chem.Soc. 105 (1983) 7512.

[22] C.O. Chike-Onyegbula, O. Ogbobe and S.C. Nwanonenyi, Biodegradable polymer drilling muds prepared from guinea corn, Journ of Brewing and distilling. 3 (2012) 6-14.

[24] V. Kumpawat, U. Garg and R.K. Tak, Corrosion inhibition of aluminium in acid media by naturally occurring plant Artocarpus heterophyllus and Acacia Senegal, Jour. Ind Council Chem. 26 (2009) 82- 4.

[25] M. Mobin, M. Parveen and M.Z.A. Rafiquee, Inhibition of mild steel corrosion using LHistidine and Synergistic additives, Journ. of Material Energy and Performance. DOI: 10.1007.11665- 012 -0262-8. 2006.

[26] S.A. Umoren, O. Ogbobe and E.E. Ebenso, Synergistic Inhibition of aluminium corrosion in acidic medium by gum Arabic and halide ion, Trans SAEST. 41 (2006) $74-81$.

[27] E.E. Oguzie, Corrosion inhibition of aluminium in acidic and alkaline media by Sansevieria trifasciata extract, Corrosion Science. 49 (2007) 1527-1539,

[28] E.E. Oguzie, V.O. Njoku, C.K. Enenebeaku, C.O. Akalezi and C. Obi, Effect of hexamethylpararosaniline chloride (crystal violet) on mild steel corrosion in acidic media, Corrosion Science. 50 (2008) 3480-86

[29] I.B. Obot, N.O. Obi-Egbedi, S.A. Umoren, Spondias mombin L. as a green corrosion inhibitor for aluminium in sulphuric acid: Correlation between inhibitive effect and electronic properties of extracts major constituents using density functional theory. Arabian Journal of Chemistry. doi: 1016/j.arabic.2010.09.002.2010.

[30] E.E. Oguzie, C.K. Enenebeaku, C.O. Akalezi, S.C. Okoro, A.A. Ayuk and E.N.Ejike, Adsorption and corrosion -inhibiting effect of dcryodis edulis extract on low carbon steel corrosion in acidic media. Jour of Colloid and Inter. Sci. 349 (2010) 283-292.

[31] D. Schweinsberg, G. George, A. Nanayakawa and D. Steinert, The protective action of epoxy resins and curing agents -Inhibitive effects on the aqueous acid corrosion of iron and steel. Corros. Sci. 28 (1998) 33-42.

[32] M.A. Quraishi and J. Rawa, Corrosion inhibition of mild steel in acid solutions by tetramethyl-dithia-octaazacyclotetradeca hexaene (MTAT). Anti-Corros. Methods Mater. 47 (2000) 288-293. 